\title{
Review: Costuming Cosplay: Dressing the Imagination, Therèsa Winge (Bloomsbury 2018)
}

\author{
Paul Mountfort* \\ Auckland University of Technology, New Zealand
}

*Corresponding author: Paul Mountfort, Chair of the AUT Centre for Creative Writing, Auckland University of Technology, New Zealand.

Received Date: July 21, 2020

Published Date: August 05, 2020

\section{Review}

Therèsa Winge enjoys something of first mover status in the annals of cosplay scholarship. Her 2006 article 'Costuming the Imagination: Origins of Manga and Anime Cosplay' in the inaugural issue of Mechademia - a journal which helped launch the serious academic study of Japanese popular culture - rates as perhaps the first rigorously scholarly treatment of the subject. Thus the appearance of her Routledge monograph in the same year as Intellect Books' Planet Cosplay: Costume Play, Identity and Global Fandom (disclosure: I am author of the latter, along with Anne Peirson-Smith and Adam Geczy) marks late 2018 as the year in which the relatively outlier field of cosplay scholarship came of age - or, at least, crossed a threshold into the realms of sustained scholarly literature.

It is worth contemplating for a moment how young cosplay scholarship is. Prior to 2006 academe treated cosplay as a tangential consideration while most of the published 'literature' consisted essentially of non-scholarly sources, such as newspaper, magazine and online articles, exemplified by Michael Bruno's pieces for Glitz and Glitter Newsletter in 2002. The few full-length books on the subject, such as Aoyama and Cahill's Cosplay Girls: Japan's Live Animation Heroines (2003) and Robert Holzek's Cosplay: The New Main Attraction (2004), were aimed at a general readership or, rather, fandom. These pop cultural forerunners of the more academic treatments that would soon appear are still quoted in journal articles due to the relative dearth of material in this pre-theoretical phase of the cosplay phenomenon. Yet during the 1990s and early 2000s the ground was being laid for a more robust framing of the popular cultural practice of fannish dressing up along three broad disciplinary axes. First was the intersection of subcultural, gender and performance studies, which cumulatively afforded scope for new understandings of gender as a performance inscribed on the physical bodies of social actors, with a particular focus on its transgressions, including queering. Second, fan practices such as fanfiction were being re-framed by Henry Jenkins' famous formulation of fans as 'textual poachers,' while related discourses around gaming, narrative and identity foregrounded the 'ludic' (or rule-based play) as both a performative and, potentially, critical practice, that resulted in a variety of appropriations and remediations. Thirdly, as noted, manga, anime and associated fandoms in Japanese otaku (hardcore nerd, geek) culture had become fashionable topics in the 1990s with Susan Napier's Anime from Akira to Princess Mononoke (2001), later reissued as Anime From Akira to Howl's Moving Castle (2005), being a much quoted keystone.

2006's inaugural issue of Mechademia, which carried Winge's 'Costuming the Imagination,' was subtitled 'Emerging Worlds of Anime and Manga.' Winge drew attention to cosplay's roots in western popular culture - and in particular sci-fi and comics convention culture - where previously many had assumed the practice to be Japanese in origin, though her focus was primarily on the cosplay of Japanese manga and anime media franchises and their subcultural followings. Fans' performances of their chosen characters were based on research and study into a source text, leading to an 'interpretation that takes place by reading and watching.' This was the same year Jenkins famously argued in Convergence Culture (2006) that, far from being the cultural dupes 
to corporate franchises many supposed them to be, fans were critical readers and (re)writers of cultural texts. The following year articles appeared on cosplay's relationship to gaming and conventions, the motif of the doll, and the specifics of U.S. and Taiwanese sites of practice, along with cosplay's first published photographic monograph, Elena Dorfman's Fandomania (2007). Since then there has been a steady stream of articles on this dynamic popular cultural practice. Winge returned, albeit glancingly, to the subject in Body Style in 2012 but prior to 2018 the only book-length treatments continued to be the - often on-demand or indie-published 'how to' guides for cosplay practice, and in particular costume-making, that continue to find a ready market among dedicated fans but which lack formal analytical value.

In some ways Costuming Cosplay represents an accommodation between these two bodies of literature, in that Winge draws amply on both the growing body of published scholarly articles and on more mass cultural material, augmented by her rich experience as a participant observer of cosplay's inhouse codes and conventions. While she is not personally a cosplayer she is deeply embedded in the culture and has acted as a convention attendee, panellist and competition judge. As she states, 'I position myself as an academic fan, or "aca-fan," whose research contributes [to] the fathropology about Cosplayers.' With regard the journalized literature, she draws widely, including such familiar figures of note as Kane Anderson, Jason Banbridge and Craig Norris, Scott Duchesne, Matthew Hale, Mari Kotani and Thomas LaMarre, Nicolle Lamerichs, Osmud Rahman et al., and Suzanne Scott. While a monograph does not require an encyclopedic review of the literature, other contributors that could profitably have been referenced include Maria Patrice Amon's work on Disney cosplay, Paul Booth on digital cosplay, Sebastian Domsch on parallels with medieval mystery plays and tableaux vivants, Patrick Galbraith on cosplay and Lolita, Emerald King on yaoi/BL (Boy Love), Ellen Kirkpatrick on the superhero genre in cosplay, Noel Gn on 'queer simulation,' Kinko Ita and Paul Crutcher on manga and pachinko tie-ins, Matthew Ogonoski on manga and anime, and Anne Peirson-Smith on the fantastical self. Effectively, therefore, Winge engages a good half of the extant critical literature, for what this somewhat blunt metric is worth.

Its author's insider status is both Costuming Cosplay's chief strength and, though to a lesser extent, a potential vulnerability. As to its many strengths, Winge is forensic in her framing of multiple dimensions of the cosplay 'subculture.' This includes the distinction between amateur and more professional (even celebrity) cosplay, hierarchy in the fandom, the role of the convention, prosumption, and fanthropological research. Some discussion of the applicability or otherwise of the much-contested 'subcultural' tag might have been useful here. News of the death of subculture may have been exaggerated but some nod towards the problematics and nuances of deploying this term today versus the alternate notions of 'style' or 'taste communities' and 'affinity groups' or 'spaces' seems in order. Winge has stated in symposia that she is aware of this issue but still finds that in the cosplay context the term subculture is fit to purpose and ultimately no less problematic than its alternatives. A little unpacking of that rationale would have been welcome in a monograph.

The heart of Costuming Cosplay is a set of 'essential constructs' or 'themes' Winge lays out in Chapter Three, It's Not Just Costume: Cosplay is a Way of Life. Winge has sifted these from a grounded analysis based on several nodes of engagement with the cosplay community, especially in North America. The United States is undoubtedly a major center in the cosplay cosmopolis and historically, along with Japan, its chief progenitor. However, given the global dimensions of the cosplay phenomenon this focus does give the book a particularly American inflection. This is not to say that Winge does not touch base with some of cosplay's other centers, with Tokyo also figuring at various points, but it is easy to gain the impression from the monograph that the U.S. is the ground zero of cosplay practice. This is, perhaps, a forgivable bias when one contemplates the vast network of conventions spread across multiple cities that make cosplay in the U.S. genuinely subcontinental in scale. Still, cosplay is as much defined today by its emergent peripheries and thus attests to a wider decentering process in global culture flows when viewed through an international lens. Cosplay cultures outside the U.S. and Japan, such as Hong Kong and Mainland China, Europe and Australasia, in many ways represent the exception that proves the rule: cosplay has gone viral and is mutating in the process. The old uni- or bi-directional models of cultural transmissions no longer hold. However, with this proviso in mind Winge's themes or 'constructs' provide an impressively detailed fanthropological analysis that gives the reader a sense of entering into the core of the U.S. cosplayer community's motivations and concerns.

These constructs focalize around costume, representation, photographs and videos, performativity and roleplay, creativity, empowerment, escapism, devotion and obsession, and fun and play. Cumulatively, this fine-grained approach is akin to peeling the proverbial layers of the onion, as Winge applies her 'grounded theory and inductive in combination with deductive analysis.' It is beyond the scope of this review to consider these themes in detail, but given that the monograph is part of Bloomsbury's Dress, Body and Culture: Critical Sourcebooks series, her consideration of how costume makes the superhero (and hence cosplay) is an appropriate launching point. Many if not all these focalizations have, of course, been considered in prior published work. There is a challenge with analyzing cosplay from these refracted perspectives inasmuch as, despite its infinite variance and sometimes subtlety, one must repeatedly resort to reformulations of the basic repertoire of the cosplay performance: source text, fannish engagement, costume construction or procurement, group or troupe interactions, the performance in the contexts provided by fan conventions, and the production, circulation, consumption and reactions of and to both still and video images - chiefly online - which flow from this. This 
can sometimes mean rehearsing the same ground over and again from slightly differing angles. However, Winge's analysis is full of fresh insight and, in this constant process of turning over, cosplay's many and varied facets are brought into sharp focus.

In terms of critical considerations, some points of contention within cosplay circles include the expense and commercialization of cosplay (hence 'costplay'), the gendered nature of cosplay practice and fan labor, the politics of consent in terms of both harassment of female participants at cons and the unauthorized use of photographic images, and the fraught enforcement of ideal body types and vicious shaming and flaming directed at some candidates from certain quarters of (especially online) fandom. These are all worthy and established tropes in discussions of cosplay that are vital to framing it within the wider cultural gestalt - and perhaps culture wars, especially in the U.S. context. However - and this is where the book's insider status, a researcher bias which Winge acknowledges, becomes something of a weakness - criticality is solely directed to defending positions within this diaspora rather than framing cosplay itself in a critical-theoretical context. As one example, there is a lot of discussion of the problems the expense of cosplay practice can pose for cosers, but little about the nesting of cosplay within a hyper capitalist neoliberal economy, both economically and culturally. After all, there are inherent tensions operative in cosplay between its arguably transgressive appropriation of transmediated content and its complicity with global franchises that are manifestations of late capitalism's media landscapes. It can be hard when you are championing something to analyses it dispassionately at one step's remove. Suzanne
Scott's arch criticism of Syfy Channel's Heroes of Cosplay's blatant gendering and wider exploitation of female labor within a kind of faux (or post-) feminist self-branding or Nicolle Lamerichs' of its appropriation into something resembling competitive sport point to possible correctives to this overly celebratory approach.

Finally, I'm wary of niggling about proofing errors and microlevel errata given the intolerable time and work pressures academic researchers labor under. However, I do feel that given the strengths of the book and its pivotal role in repositioning cosplay in the academic context Winge has been let down by her copy-editors at Bloomsbury, with the regrettable (and false, given its basis in more than a decade of hard-won research) impression being of a work somewhat rushed to press.

These inevitable quibbles should not, however, distract from what this book accomplishes. On publication it has become instant indispensable reading for cosplay scholars and it is likely to remain a touchstone for many years to come. Costuming Cosplay cements Winge's status as both historical explorer and contemporary champion of this fascinating popular cultural practice, and her work does admirable justice to its associated community, especially in its home territory of the U.S.

\section{Acknowledgement}

None.

\section{Conflict of Interest}

Author declare no conflict of interest. 